\title{
The Relationship between Task Characteristics, BI Quality, and Task Compatibility: An Explorative Study
}

\author{
Rikke Gaardboe ${ }^{1 *}$, Tanja Svarre ${ }^{2}$, and Tom Nyvang ${ }^{2}$ \\ ${ }^{1}$ Department of Business and Management, Aalborg University, Fibigerstraede 11, \\ Aalborg Oest, 9220, Denmark \\ ${ }^{2}$ Department of Communication and Psychology, Aalborg University, \\ Rendsburggade 14, Aalborg, 9000, Denmark \\ gaardboe@business.aau.dk, tanjasj@hum.aau.dk, nyvang@hum.aau.dk
}

\begin{abstract}
The purpose of this article is to investigate the relationship between task characteristics, business intelligence (BI) quality, and task compatibility. It is essential to investigate this relationship, as BI often builds up data from the organization's existing information systems, and thus, is a supplement. In addition, there is a gap within existing research about task characteristics and BI. We conducted a survey of three companies, where 104 BI end users answered the questionnaire. Our findings reveal that BI users who experience high information quality solve difficult tasks, have a specified job, and their task solution is independent of others experiencing higher task compatibility. The main contribution of the survey is a better understanding of how tasks and BI fit together. In conclusion, the model could be tested in different industries and with different information systems.
\end{abstract}

Keywords: Task difficulty, Task specificity, Business intelligence, Digital transformation.

\section{Introduction}

Accumulation, structuration, and access to data drive the introduction of new business models, transform the marketing of existing products, and offer new opportunities for internal learning, regulation, and optimization in organizations. Thus, top level management and information technology (IT) management have a massive task in both accumulation and provision of access to data in relevant structures and formats, so that decision-makers, analysts and many others in the organization can utilize data towards digital transformation [1]. The 25 highest-ranked

\footnotetext{
* Corresponding author
}

(C) 2018 Rikke Gaardboe et al. This is an Open Access article licensed under the Creative Commons Attribution License (CC BY 4.0), https://creativecommons.org/licenses/by/4.0

Reference: R. Gaardboe, T. Svarre, and T. Nyvang, "The Relationship between Task Characteristics, BI Quality and Task Compatibility: An Explorative Study," Complex Systems Informatics and Modeling Quarterly, CSIMQ, no. 14, pp. 54-63, 2018. Available: https://doi.org/10.7250/csimq.2018-14.04

Additional information. Authors ORCID iD: R. Gaardboe - orcid.org/0000-0002-9989-9647, T. Svarre - orcid.org/0000-00025468-0406, and T. Nyvang - orcid.org/0000-0002-2684-7379. PII S225599221800083X. Received: 12 February 2018. Accepted: 6 April 2018. Available online: 30 April 2018. 
transformation factors include work, coordination, digital uses, and internal innovation practices; and across these 25 factors, exchange and utilization of data and/or digital tools is a common denominator in at least 17 factors. Thus, for organizations' success, it is essential to use IT to learn from data and to apply the results of that learning purposefully and successfully. Business intelligence (BI) is a genre of systems that structures, integrates and provides access to data. Support for further analysis of data can also be provided by BI. BI supports decision-making at all levels in an organization [2]. Top level management uses BI to monitor key performance indicators or other measures towards objectives. On lower levels, BI supports decision-making of a more tactical nature regarding things such as organizational structure and overall technical setup. Further down, at the operational level, BI supports reporting and ad hoc follow up during daily operations [3]. The diversity of decision-making tasks show that the use of BI calls for further analysis of the tasks supported by BI. In information systems (IS) research, task (and task-structure) is already a concept receiving much attention for several reasons. First, the analysis of tasks serves to define the roles and functionalities of the IS. Secondly, task structure or work activity determinants, in a broader sense, [4] are the keys to understanding and evaluating the IS success [5].

To benefit from BI, there must be a good fit between the tasks at hand and the BI [6]. This is also referred to as task compatibility [3], [7], [8], [9] in relation to IS success, but, unlike general IS research, the research specifically on BI has not yet addressed the fit between task characteristics and the BI (technology). This article is an extended version of the paper presented at the International Conference on Perspectives in Business Informatics Research 2017 [1].With this article, we develop a research model and report research on the fit between business intelligence quality and task characteristics.

\section{Modeling BI Tasks}

\subsection{Literature Review}

A systematic literature review was performed to address the critical success factors (CSF) in BI [10]. The focus was on peer-reviewed papers published between 2006-2015. We followed Papaioannou et al.'s [2] search strategy that included databases, reference lists, and citations, which formed the basis for identifying relevant papers. The queries applied consisted of two facets [3]: one included synonyms for CSFs, while the other represented BI. The search for CSFs was based on the following terms: 'success factor,' 'success factors,' 'IS success,' 'information system success' and 'information systems success.' The other part of the query searched for the following technology keywords: 'data warehouse,' 'data warehouses,' and 'business intelligence.' Papers were selected first by the relevance of the abstract, then by the relevance of the full paper. We searched the following academic databases with advanced search interfaces: Web of Science (ISI), Scopus (Elsevier), ACM Digital Library, EBSCOhost, and ABI/INFORM Complete (ProQuest). Of 336 papers and 1184 references, 29 papers fit the scope of the review. Petter, DeLone and McLean's [5] framework of IS success was used as the guide for the identification of CSFs and the analysis and subsequent mapping of how researchers have identified success in BI systems. CSFs were categorized as distinct if occurring in at least $20 \%$ of the 29 papers.

The review findings driving the model introduced below include: (i) CSF research has a limited focus on task compatibility as an independent factor for BI success: this is explained further in Section 2.2; (ii) since users frequently have access to the source system and BI, no existing research studied characteristics of BI supported tasks; and lastly (iii), the quality dimension is the most dominant factor describing BI success, either by system quality or information quality. 


\subsection{The Relationship between Task Characteristics, BI Quality and Task Compatibility}

Tasks are the activities supporting organizations and a job is comprised of a number of tasks [6]. Thus, the purpose of using the IS is the completion of tasks [4]. Furthermore, the goal of the IS implementation is to automate tasks or to acquire task information [7]. Because of the relationship between tasks and IS, various antecedents of IS success are associated with task structure and characteristics [8]. In the contingency theory literature, the close relationship between task/fit and performance is emphasized [9]. For instance, misfits can occur when a user wants to use information from the BI to check key performance indicators (KPIs), but the data is missing [11].

The review demonstrated that BI literature has not comprehensively investigated tasks as CSFs [10]. Many studies have examined task characteristics and their related impact on the use of IS, and there have been various suggestions as to how to operationalize the concept [12]. Petter et al. [5] found six determinants of the task category to determine IS success, including task compatibility, task difficulty, task interdependence, task significance, task variability, and task specificity. In the review, task compatibility did not count as a distinct CSF, having only been studied in four papers [10]. Task compatibility diverges from the remaining determinants by examining the fit between technology and the task, whereas the other determinants describe the task independently of the technology.

The task characteristics construct is constituted by a number of variables. Task interdependence defines to what extent the task supported by BI depends on the completion of other tasks. Task difficulty is to what degree the task supported by BI is challenging for users of the system. Task significance designates the necessity of the BI task. Task variability is the degree of consistency between a user's task and a general work process. Task specificity represents the details of the task [5].

In the literature, system quality represents an essential parameter for BI success [13]. According to Lee, Strong, Kahn and Wang [14], information quality (IQ) is formed by four individual dimensions, including intrinsic IQ, contextual IQ, representational IQ, and accessibility IQ. Intrinsic IQ is identical to DeLone and McLean's [15] information quality dimension. Contextual IQ is identical to Goodhue's [12] concept of task/fit. The remaining two dimensions are identical to DeLone and McLean's system quality. Lee, Strong, Kahn and Wang [16] do not consider service quality as a quality dimension such as DeLone and McLean [17] do in their updated IS success model. The information quality produced by the system [18], represents a significant factor when the system is evaluated [19]. In the review, 16 papers studied information quality as a BI success factor [10]. Thus, it represents a distinct element in the BI literature. System quality addresses issues like user interface system errors, ease of use, and quality and maintenance of program codes [19]. In the review, 28 out of 29 papers found system quality to be a CSF [13]. Accordingly, the review identifies system quality as the most well investigated concept of all BI system success determinants of the Petter, DeLone and McLean's [5] framework.

Task compatibility emphasizes the requirement of evaluating information quality in the task context. BI should hold the necessary qualities to complete the user's task [12]. When these requirements are met, the system and the task add value. Information should be relevant, timely, complete, and of an appropriate amount [14]. These features of information lead to task compatibility. When BI has sufficient information, it fits the user's needs. Completeness, in this sense, differs from a suitable amount, as it measures the information, including all necessary values. Timeliness focuses on the information being up-to-date for the user's expectations. Lastly, relevance addresses whether the information is relevant to the user's need to fulfill the task with the BI support [14]. 


\subsection{Task/BI Compatibility Model}

The model presented below (Figure 1) involves six constructs. BI quality is divided into system quality and information quality since system quality represents an evaluation of the BI system, and information quality evaluates BI information. Further, the four task characteristics are presented. All constructs affect task compatibility.

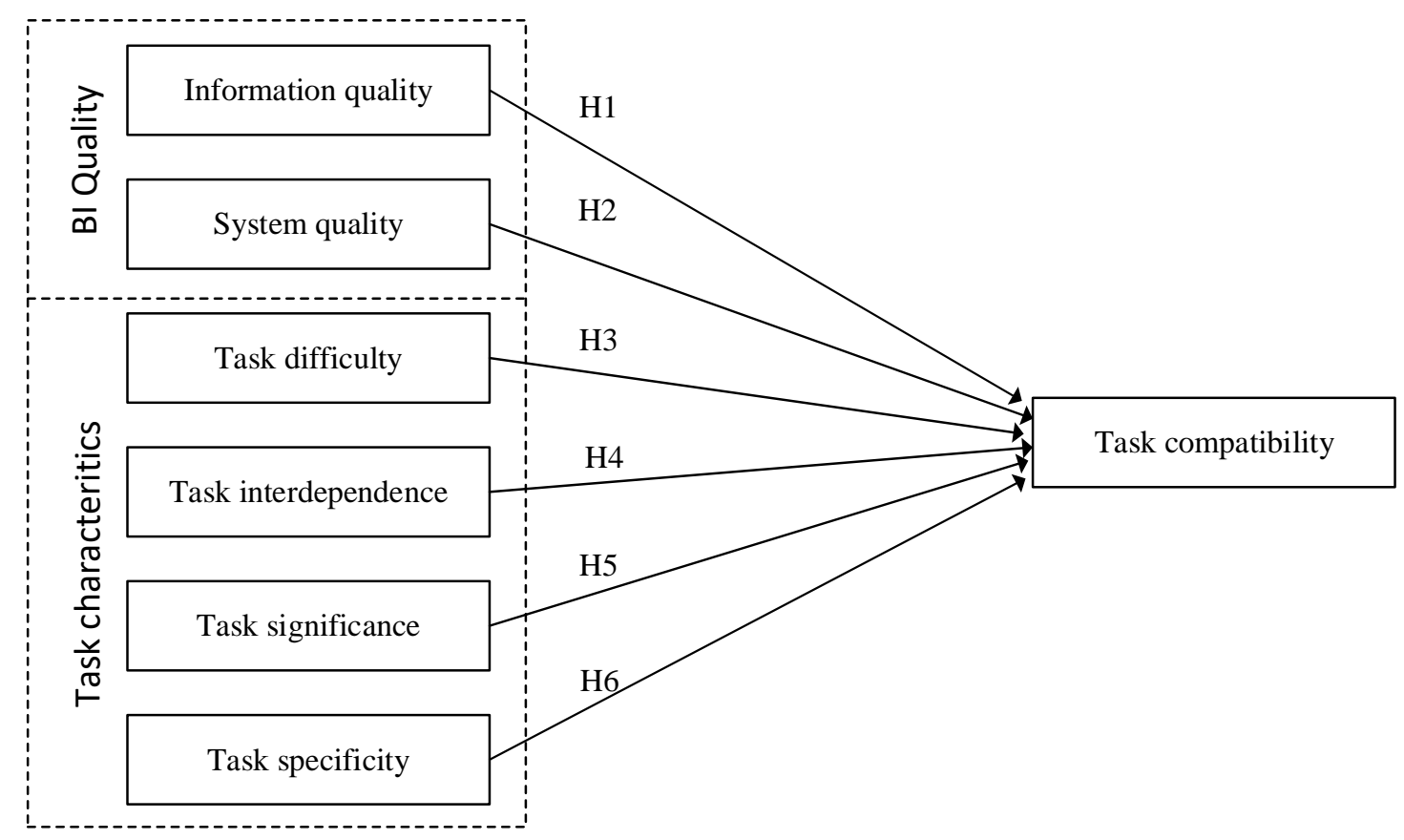

Figure 1. Task/BI Compatibility Model

Based on the relationships illustrated in Figure 1, the following hypotheses are tested in the article:

H1: There is a positive relationship between information quality and task compatibility

$\mathrm{H} 2$ : There is a positive relationship between system quality and task compatibility

H3: There is a positive relationship between task difficulty and task compatibility

$\mathrm{H} 4$ : There is a positive relationship between task interdependence and task compatibility

H5: There is a positive relationship between task significance and task compatibility

H6: There is a positive relationship between task specificity and task compatibility.

\section{Methodology}

\subsection{Data Collection}

Data were collected from a questionnaire. The study was prepared according to the procedure outlined by Dillmann [16], and all questions were based on related research. Thus, they have been tested and validated by other studies. Further, all the items were selected and evaluated by three researchers within the field. The questions were measured on a 5-point Likert scale, where only the endpoints were labeled. Before sending the questionnaire, we conducted a pilot study with 24 BI users who had different experiences with BI. Based on the pilot study, the final questionnaire was prepared. We used an online survey program to collect respondents' responses. In Table 1, the questions are presented. 
Table 1. Questionnaires used in the survey

\begin{tabular}{|c|c|c|c|}
\hline Construct & Item & Question & Reference \\
\hline \multirow[t]{3}{*}{ System quality } & SysQua01 & BI is easy to learn. & [20] \\
\hline & SysQua02 & BI is easy to use. & [21] \\
\hline & SysQua03 & The information in BI is easy to understand. & [22] \\
\hline \multirow[t]{3}{*}{ Information quality } & InfQua01 & Data are displayed in a consistent format in BI. & [22] \\
\hline & InfQua02 & Data in BI have high validity. & [22] \\
\hline & InfQua03 & $\begin{array}{l}\text { Other employees at the organization also think the } \\
\text { data in BI have high validity. }\end{array}$ & [22] \\
\hline \multirow[t]{4}{*}{ Task compatibility } & TaskCom01 & This information is useful for my tasks. & [22] \\
\hline & TaskCom02 & This information is complete for my needs. & [22] \\
\hline & TaskCom03 & This information is relevant to my tasks. & [22] \\
\hline & TaskCom04 & $\begin{array}{l}\text { This information is sufficiently up to date for my } \\
\text { tasks. }\end{array}$ & {$[22]$} \\
\hline \multirow[t]{3}{*}{ Task difficulty } & TaskDif01 & BI makes it possible to complete complicated tasks. & [23] \\
\hline & TaskDif02 & $\begin{array}{l}\text { The tasks I complete in BI require specialized } \\
\text { knowledge. }\end{array}$ & [23] \\
\hline & TaskDif03 & $\begin{array}{l}\text { The tasks I solve in BI are ones I have never done } \\
\text { before }\end{array}$ & [23] \\
\hline \multirow[t]{3}{*}{$\begin{array}{l}\text { Task } \\
\text { interdependence }\end{array}$} & TaskInt01 & $\begin{array}{l}\text { If I do not complete my tasks in BI, one or more } \\
\text { employees in the organization cannot complete } \\
\text { their tasks. }\end{array}$ & [23] \\
\hline & TaskInt02 & $\begin{array}{l}\text { In BI, I can only do tasks if one or more employees } \\
\text { have completed another task first. }\end{array}$ & [23] \\
\hline & TaskInt03 & $\begin{array}{l}\text { I am independent of other employees to prepare } \\
\text { tasks in BI. }\end{array}$ & [23] \\
\hline \multirow[t]{5}{*}{ Task significance } & TaskSig01 & $\begin{array}{l}\text { The tasks I complete in BI are an important part of } \\
\text { my tasks. }\end{array}$ & [23] \\
\hline & TaskSig02 & I make decisions by the tasks I complete in BI. & [23] \\
\hline & TaskSig03 & $\begin{array}{l}\text { My tasks completed in BI are important to other } \\
\text { employees in the organization. }\end{array}$ & [23] \\
\hline & TaskSig04 & $\begin{array}{l}\text { Other people make decisions based on the tasks I } \\
\text { completed in BI. }\end{array}$ & [23] \\
\hline & TaskSig05 & $\begin{array}{l}\text { My tasks in BI are important for collaborators } \\
\text { outside the organization. }\end{array}$ & [23] \\
\hline \multirow[t]{3}{*}{ Task specificity } & TaskSpe01 & $\begin{array}{l}\text { My tasks are always defined before I complete } \\
\text { them in BI. }\end{array}$ & [23] \\
\hline & TaskSpe02 & $\begin{array}{l}\text { The tasks I complete in BI can be done in more } \\
\text { than one way. }\end{array}$ & [24] \\
\hline & TaskSpe03 & $\begin{array}{l}\text { Normally, I do not complete the same kinds of tasks } \\
\text { in BI. }\end{array}$ & [23] \\
\hline
\end{tabular}

The research was conducted in three companies in different sectors. They used various BI tools including Cognos, Business Objects, and Power BI. The selection criterion for selecting respondents was access rights to the BI systems. All respondents were informed in advance by the company that a data collection would be made for research purposes. Thereafter, an email with a link to the questionnaire was sent to BI users. If the respondents had not responded to the survey after a week, we sent a reminder. There were 522 potential users of BI and 269 answered the questionnaire. Thus, there was a response rate of $51 \%$. Of this group, only 104 were real BIusers who used this system for statistical analysis. The second lot of users had access rights to BI, but they did not use the system. Only those respondents that had responded that they had used the system were considered for further statistical analyzes. According to Hair et al. [25], it is necessary to inquire of 10 times more users than the number of relationships in the research model. There are six relationships in the model in Figure 1, thus the minimum amount of respondents would be 60 . Therefore, the sample size was sufficient to execute the Partial Least 
Squares Structural Equation Modelling technique (PLS). SmartPLS version 3.2.7 was used for the PLS analysis.

\subsection{Assessment of the Reliability and Validity of the PLS Model}

We tested the model represented in Figure 1 with PLS (see Figure 2).

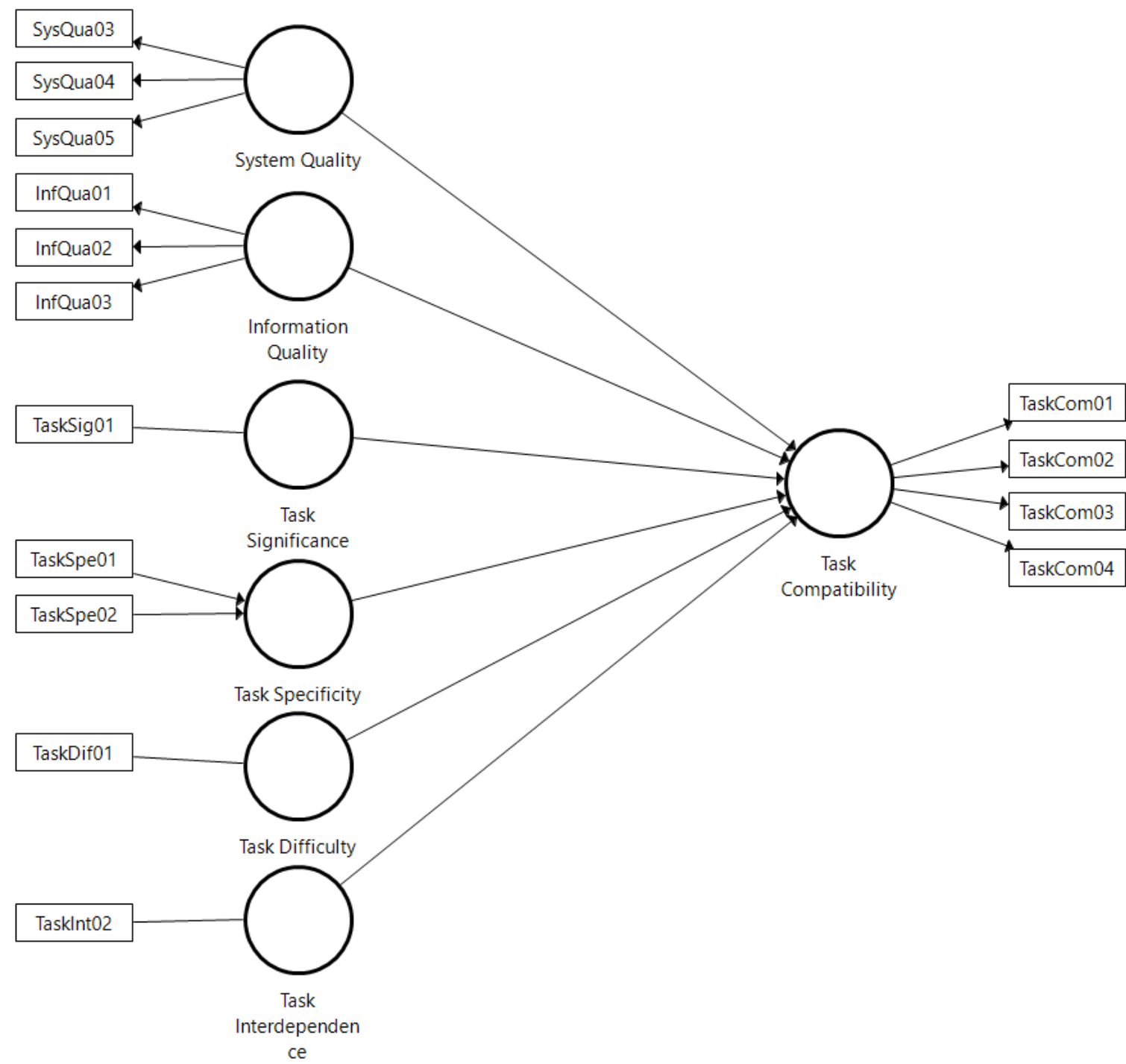

Figure 2. The tested PLS model

The starting point for PLS was a structural theory, showing how latent variables are related to each other. PLS is one of the two main approaches for estimating the real-world in a structural equation model [25]. Before examining the relationships in the model, using PLS, the validity and reliability were assessed [26]. Before examining the relationships in the structural equation model, the reflective and formative measurement model was evaluated. Guidelines of Hair et al. [25] were followed. Hence, task difficulty, task interdependence, and task significance were oneitem constructs and could not be evaluated. We evaluated the reflective measurement model by using internal consistency, convergent validity, and discriminant validity. 
Table 2. Assessment of reflective measurement model

\begin{tabular}{|c|c|c|c|c|c|c|}
\hline \multirow{3}{*}{ Construct } & \multirow{3}{*}{ Item } & \multicolumn{2}{|c|}{ Convergent validity } & \multicolumn{2}{|c|}{$\begin{array}{c}\text { Internal consistency } \\
\text { reliability }\end{array}$} & $\begin{array}{c}\text { Discriminan } \\
\text { validity }\end{array}$ \\
\hline & & Outer loading & AVE & $\begin{array}{l}\text { Composite } \\
\text { Reliability } \\
\end{array}$ & $\begin{array}{c}\text { Cronbach } \\
\text { Alpha }\end{array}$ & \multirow{2}{*}{$\begin{array}{c}\text { HTMT } \\
\text { includes } 1\end{array}$} \\
\hline & & $0.7<$ & $0.5<$ & $0.70<$ & $0.70<$ & \\
\hline \multirow{3}{*}{$\begin{array}{l}\text { Information } \\
\text { Quality }\end{array}$} & InfQua01 & 0.786 & \multirow{3}{*}{0.769} & \multirow{3}{*}{0.908} & \multirow{3}{*}{0.847} & No \\
\hline & InfQua02 & 0.915 & & & & No \\
\hline & InfQua03 & 0.923 & & & & No \\
\hline \multirow{3}{*}{ System Quality } & SysQua03 & 0.927 & \multirow{3}{*}{0.881} & \multirow{3}{*}{0.928} & \multirow{3}{*}{0.882} & No \\
\hline & \begin{tabular}{|l|} 
SysQua04 \\
\end{tabular} & 0.923 & & & & No \\
\hline & SysQua05 & 0.849 & & & & No \\
\hline \multirow{4}{*}{$\begin{array}{l}\text { Task } \\
\text { Compatibility }\end{array}$} & TaskCom01 & 0.761 & \multirow{4}{*}{0.660} & \multirow{4}{*}{0.885} & \multirow{4}{*}{0.826} & No \\
\hline & TaskCom02 & 0.847 & & & & No \\
\hline & TaskCom03 & 0.724 & & & & No \\
\hline & TaskCom04 & 0.905 & & & & No \\
\hline
\end{tabular}

In Table 2, the reflective measurement model is assessed. All items are above the threshold values recommended by Hair et al. [25]. According to Hair et al. [25], the heterotrait-monotrait ratio of correlations (HTMT) is more recent than other methods for assessing discriminant validity in PLS. HTMT were also evaluated, and in all cases, the interval did not include 1.

The formative measurement model was evaluated based on collinearity, significance and relevance and outer weights. Task specificity was the only formative construct. VIF is in both cases below 5, with the value 1.049. The outer weight was also assessed, and in both cases, they were significant $(p<0.001)$. Task significance, task difficulty, and task interdependence are single-item constructs, and therefore, were not tested.

\section{Results}

The PLS based testing of the hypotheses is summarized in Table 3 which reflects coefficients and p-values. The $\mathrm{R}^{2}$ adj. of task compatibility is 0.729 . Therefore, the model has a high degree of explanation.

Table 3. Tested hypotheses

\begin{tabular}{|l|r|r|l|}
\hline \multicolumn{1}{|c|}{ Hypothesis } & Coeff. & P Values & \multicolumn{1}{c|}{ Significance } \\
\hline Information Quality -> Task Compatibility & 0.426 & 0.000 & Significant \\
\hline System Quality -> Task Compatibility & 0.042 & 0.645 & Insignificant \\
\hline Task Difficulty -> Task Compatibility & 0.401 & 0.000 & Significant \\
\hline Task Interdependence -> Task Compatibility & -0.128 & 0.029 & Significant \\
\hline Task Significance -> Task Compatibility & 0.032 & 0.642 & Insignificant \\
\hline Task Specificity -> Task Compatibility & 0.133 & 0.012 & Significant \\
\hline
\end{tabular}

There exists a positive and significant relationship between information quality and task compatibility $(p<0.001)$. A higher information quality contributed to the increase in the BI users' perception of task compatibility. Furthermore, we found a positive and significant relationship between task difficulty and task compatibility $(p<0.001)$. Thus, the more difficult the task the user solves with BI, the better the fit between the tasks and BI is perceived. Surprisingly, we found a negative and significant relationship between task interdependence and task compatibility $(p<0.05)$. The more independent the task is, the better task compatibility becomes. Finally, we found a positive and significant relationship between task specificity and task 
compatibility. Users' perception of how specific a task is, affects the task compatibility. If the task is highly specified, the user also experiences a good fit between technology and tasks. The relationship between system quality and task compatibly is insignificant. The same applies to the relationship between task significance and task compatibility.

We also assessed the effect size, which is referred to as $f^{2}$ [25]. The guidelines provided by Cohen [27] were followed. Information quality and task difficulty has a medium effect on task compatibility $\left(f^{2}=0.301\right)$ and $\left(f^{2}=0.345\right)$. While task interdependence and task specificity have a low effect on task compatibility $\left(f^{2}=0.055\right)$ and $\left(f^{2}=0.058\right)$, the other constructs do not affect task compatibility.

Another relevant measure is the predictive relevance $\left(Q^{2}\right)$ of a dependent construct. If the value of $Q^{2}$ is higher than zero, it indicates the path model's predictive relevance for the dependent construct [25]. In the model, $Q^{2}$ is equal to 0.444 and therefore, above zero. In conclusion, the model has predictive value.

\section{Discussion}

Task compatibility is an important construct, leading to higher individual impact from a user's perspective, which several studies have confirmed [12], [28], [29].

Task difficulty was found to have a positive and significant relationship with task compatibility. That implies that users see more potential in BI when the task at hand is difficult. This result contradicts Goodhue and Thompson [12], who found that non-routine tasks generated lower assessments of the compatibility. Several conditions may add to the explanation of this difference. One reason may be the difference of the definition of the concept of compatibility in Petter et al. [5] and Goodhue and Thompson [12]. With the former, compatibility is associated to the task, whereas the latter authors connect compatibility to the internal characteristics of data. Another possible reason is that Goodhue and Thompson [12] investigated a variety of technologies, whereas the current data solely considers BI systems.

Task interdependence measures whether the BI user is dependent on colleagues' tasks before the reports are made in BI. The relationship is negative and significant. Therefore, if the user can perform the tasks independently of their colleagues' work, then the task compatibility is higher.

Information quality was measured by the consistency of data, the user's own and others' perceived validity of data. Thus, the positive and significant relationship with task compatibility is not surprising, as the information quality would be expected to be an essential premise for completing a task. The data confirmed this assumption. The analysis also confirmed that the more specific the task is, the higher the user assesses its fit with the BI. Several explanations can be made for this finding. One explanation could be that the more precise or specific the task is, the easier it is for the user to identify the information that can solve the task. Conversely, the more explorative a task is, the more difficult it may be for the user to determine the relevant information for the task. Related to this, the user's experience with the task may influence the assessment of task specificity and, thereby, also the relationship with task compatibility.

As mentioned above, no relationship was found between system quality and task significance and task compatibility. According to Petter et al. [5], task significance is often related to the intention to use, user satisfaction, and individual impact [30], [31]. Therefore, it makes sense to assume that the significance of a task does not influence the fit between the task and technology. The unexpected insignificant relationship between system quality and task compatibility could be investigated further. Perhaps the mandated nature of BI could influence the lack of significance in both cases.

The topic of tasks and BI is essential because, in many organizations, BI is based on the organization's data, and is, therefore, a supplement to the other information systems. To ensure the highest possible individual time impact for the individual employee, it is essential to understand this relationship. The article has several contributions about the relationship between tasks and BI. Firstly, we can see that higher information quality provides higher task 
compatibility. The same applies to the two task characteristics, task difficulty and task significance. Concerning task interdependency, the employees will provide higher task compatibility if they are independent of other employees to complete the task. These characteristics are important in an organization that has implemented BI in order to ensure optimal use of technology. Secondly, the model has a high degree of explanation. Moreover, the two highest effects in relation to task compatibility are information quality and task difficulty, followed by task interdependence and task specificity. Thirdly, the article has a methodical contribution, as it is the first article, as we know, to operationalize task characteristics at such a level that it can cover the tasks across organizations and employee groups. As mentioned earlier, there are only a few studies on the connection between different task characteristics; for instance, task compatibility, use, user satisfaction and individual impact. Therefore, more research is needed to investigate the role of tasks in different information systems and in different contexts.

\section{Conclusion}

For many organizations, it is essential to handle large amounts of data and use the information from that data to improve competitiveness. Based on a literature review, we have developed a task / BI compatibility model that consists of four task characteristics, including information quality, system quality, and their relationship with task compatibility.

The model was tested using PLS and has a discriminant coefficient of 0.729 . The models shows that users who experience high information quality solve difficult tasks and have a specified job, while the task solution is independent of others experiencing higher task compatibility. In future work the model can be tested in different industries and with different information systems.

\section{References}

[1] R. Gaardboe, T. Svarre, and T. Nyvang, "Task characteristics that fit use of Business Intelligence," in Joint Proceedings of the BIR 2017 pre-BIR Forum, Workshops and Doctoral Consortium co-located with 16th International Conference on Perspectives in Business Informatics Research (BIR 2017), CEUR Workshop Proceedings, vol. 1898, 2017.

[2] D. Papaioannou, A. Sutton, C. Carroll, A. Booth, and R. Wong, "Literature searching for social science systematic reviews: consideration of a range of search techniques," Health Information \& Libraries Journal, vol. 27, no. 2, pp. 114-122, Jun. 2010. Available: https://doi.org/10.1111/j.1471-1842.2009.00863.x

[3] K. Markey, Online Searching: A Guide to Finding Quality Information Efficiently an Effectively. Lanham: Rowman \& Littlefield, 2015.

[4] H. J. Leavitt, "Applied organizational change in industry: Structural, technological and humanistic approaches," in Handbook of Organizations, J. March, Ed. 1965, pp. 1144-1170.

[5] S. Petter, W. DeLone, and E. R. McLean, "Information Systems Success: The Quest for the Independent Variables," Journal of Management Information Systems, vol. 29, no. 4, pp. 7-62, Apr. 2013. Available: https://doi.org/10.2753/MIS0742-1222290401

[6] M. T. Brannick, "Job Analysis," in The SAGE Encyclopedia of Theory in Psychology, 2455 Teller Road, Thousand Oaks, California 91320: SAGE Publications, Inc., $2016 . \quad$ Available: https://doi.org/10.4135/9781483346274.n167

[7] S. Zuboff, In the age of the smart machine: the future of work and power. Oxford: Heinemann, 1988.

[8] K. R. T. Larsen, "A Taxonomy of Antecedents of Information Systems Success: Variable Analysis Studies," Journal of Management Information Systems, vol. 20, no. 2, pp. 169-246. Available: https://doi.org/10.1080/07421222.2003.11045768

[9] L. Donaldson, The contingency theory of organizations. Thousand Oaks, Calif: Sage Publications, 2001. Available: https://doi.org/10.4135/9781452229249

[10] R. Gaardboe and T. Svarre, "Critical Success factors for Business Intelligence Success," in Proceedings of the 25th European Conference on Information Systems. The Association for Information Systems (AIS), 2017, pp. 472-486. 
[11] R. Gaardboe, T. Nyvang, and N. Sandalgaard, "Business Intelligence Success applied to Healthcare Information Systems," Procedia Computer Science, vol. 121, pp. 483-490, 2017. Available: https://doi.org/10.1016/j.procs.2017.11.065

[12] D. L. Goodhue and R. L. Thompson, “Task-Technology Fit and Individual Performance," MIS Quarterly, vol. 19, no. 2, pp. 213-236, Jun. 1995. Available: https://doi.org/10.2307/249689

[13] R. Gaardboe and T. Svarre, "Critical Success factors for Business Intelligence Success," in Proceedings of the 25th European Conference on Information Systems. The Association for Information Systems (AIS), 2017, pp. $1-17$.

[14] Y. W. Lee, D. M. Strong, B. K. Kahn, and R. Y. Wang, "AIMQ: a methodology for information quality assessment," Information \& management, vol. 40, no. 2, pp. 133-146, 2002. Available: https://doi.org/10.1016/S0378-7206(02)00043-5

[15] W. H. DeLone and E. R. McLean, "Information Systems Success: The Quest for the Dependent Variable," Information Systems Research, vol. 3, no. 1, pp. 60-95, Mar. 1992. Available: https://doi.org/10.1287/isre.3.1.60

[16] D. A. Dillman, J. D. Smyth, and L. M. Christian, Internet, phone, mail, and mixed-mode surveys: the tailored design method, 4th edition. Hoboken: Wiley, 2014.

[17] W. H. DeLone and E. R. McLean, "The DeLone and McLean Model of Information Systems Success: A TenYear Update," Journal of Management Information Systems, vol. 19, no. 4, pp. 9-30, 2003. Available: https://doi.org/10.1080/07421222.2003.11045748

[18] O. Tona, S. A. Carlsson, and S. Eom, "An empirical test of Delone and McLean's information system success model in a public organization," in 18th Americas Conference on Information Systems 2012, AMCIS 2012, 2012, pp. 1374-1382.

[19] P. B. Seddon, "A Respecification and Extension of the DeLone and McLean Model of IS Success," Information Systems Research, vol. 8, no. 3, pp. 240-253, 1997. Available: https://doi.org/10.1287/isre.8.3.240

[20] J. R. Lewis, "IBM Computer Usability Satisfaction Questionnaires: Psychometric Evaluation and Instructions for Use," International Journal of Human-Computer Interaction, vol. 7, no. 1, pp. 57-78, 1995. Available: https://doi.org/10.1080/10447319509526110

[21] Y.-S. Wang and Y.-W. Liao, "Assessing eGovernment systems success: A validation of the DeLone and McLean model of information systems success," Government Information Quarterly, vol. 25, no. 4, pp. 717733, Oct. 2008. Available: https://doi.org/10.1016/j.giq.2007.06.002

[22] Y. W. Lee, D. M. Strong, B. K. Kahn, and R. Y. Wang, "AIMQ: a methodology for information quality assessment," Information \& management, vol. 40, no. 2, pp. 133-146, 2002. Available: https://doi.org/10.1016/S0378-7206(02)00043-5

[23] F. P. Morgeson and S. E. Humphrey, "The Work Design Questionnaire (WDQ): Developing and validating a comprehensive measure for assessing job design and the nature of work.," Journal of Applied Psychology, vol. 91, no. 6, pp. 1321-1339, 2006. Available: https://doi.org/10.1037/0021-9010.91.6.1321

[24] R. L. Daft and N. B. Macintosh, "A Tentative Exploration into the Amount and Equivocality of Information Processing in Organizational Work Units,” Administrative Science Quarterly, vol. 26, no. 2, pp. 207-224, 1981. Available: https://doi.org/10.2307/2392469

[25] J. Hair, T. Hult, C. Ringle, and M. Sarstedt, A primer on partial least squares structural equation modeling (PLS-SEM). Thousand Oaks, CA: SAGE Publications, Inc., 2017.

[26] C. Fornell and D. F. Larcker, "Structural equation models with unobservable variables and measurement error: Algebra and statistics," Journal of marketing research, vol. 18, no. 3, pp. 382-388, 1981. Available: https://doi.org/10.2307/3150980

[27] J. Cohen, Statistical power analysis for the behavioral sciences, 2nd ed. Hillsdale, N.J: L. Erlbaum Associates, 1988.

[28] P. Y. Chau and P. J. Hu, "Examining a model of information technology acceptance by individual professionals: An exploratory study," Journal of management information systems, vol. 18, no. 4, pp. 191-229, 2002. Available: https://doi.org/10.1080/07421222.2002.11045699

[29] W. Hong, J. Y. L. Thong, W.-M. Wong, and K.-Y. Tam, "Determinants of user acceptance of digital libraries: an empirical examination of individual differences and system characteristics," Journal of Management Information Systems, vol. 18, no. 3, pp. 97-124, $2002 . \quad$ Available: https://doi.org/10.1080/07421222.2002.11045692

[30] V. Venkatesh and F. D. Davis, "A theoretical extension of the technology acceptance model: Four longitudinal field studies," Management science, vol. 46, no. 2, pp. 186-204, 2000. Available: https://doi.org/10.1287/mnsc.46.2.186.11926

[31] Y. Yoon and T. Guimaraes, "Assessing expert systems impact on users' jobs," Journal of management information systems, vol. 12, no. 1, pp. 225-249, $1995 . \quad$ Available: https://doi.org/10.1080/07421222.1995.11518076 